\title{
Comparative tests of samples of high-speed tool steel with high-speed steel with DLC coating in terms of abrasion resistance.
}

\author{
Nowak Martyna ${ }^{1}$ \\ 1. Faculty of Transport, Silesian University of Technology, POLAND, Katowice, Krasińskiego street 8, \\ E-mail: nowak.martyna23@gmail.com
}

\begin{abstract}
The paper presents the problem of abrasive wear of the surface of high-speed steel in the tribological approach and the methods of minimizing its effects have been determined. Detailed tests were carried out together with the analysis of an uncoated high-speed steel specimen and samples with DLC coating (Diamond-Like Carbon).
\end{abstract}

Keywords - DLC coating, high speed steel, abrasive wear, friction, abrasion test

\section{Introduction}

Due to the common technical problem, which is the wear of elements in terms of their abrasiveness, experts are looking for solutions, many of which do not bring the expected results. At a time when technicians strive to achieve the best performance of machine components without loaded them, the eyes of all scientists are directed to the field of materials science. The research involving the coating of a selected steel coating that is characterized by better chemical and physical properties is becoming more and more popular.

\section{Characteristics of high-speed steel}

High-speed steels are high-alloy steels. Elements made of high-speed steel are themabrasion resistance, high temperatures and adequate hardness. All these features provide them with a content of about $30 \%$ of alloy additives, such as: carbon, chromium, vanadium, tungsten, molybdenum and cobalt. High-speed steels have a very high technical importance due to their versatility and flexibility of applications. They are used on many levels of the technical industry, and their popularity is constantly growing. A wide range of good properties of highspeed steel broadens its use. Examples of the most popular applications of high-speed steel are: drills, milling cutters, turning tools and taps, but also heavily loaded and abrasive parts of machines, such as bearings, rings and spring elements. [1][2]

\section{Abrasive wear phenomenon}

Abrasive wear of a material is included in the chemical-mechanical processes and is presented as the degree of mass loss, thickness or volume of the element that results from the friction existing between the cooperating elements. Exploitation resulting in wiping is based on the mutual friction of two or more parts cooperating with each other. In most of these systems there is also a rapid increase in temperature due to the high load and the forces occurring.

Tribological wear is a problem that occurs chronically in every field of technology and mechanics, and its effects exclude from operation periodically or completely hundreds of mechanisms every year. It occurs when at the place of friction of two or more elements abrasive particles appear, pollen resulting from wear of elements or surface irregularities resulting from an incomplete execution. In order to prevent the phenomenon of quick rubbing of the element, carefully choose the material from which it should be made. [2] 
Tests carried out prior to the implementation of the element should primarily concern abrasion resistance, temperature resistance, hardness and composition in terms of the type of load that will be encountered. It is also important to precisely determine the material of the cooperating element and the lubrication between them. Detailed tribological tests of materials for components loaded with friction and their thorough analysis are carried out in order to minimize the effects of friction and, as a result, extend the life of machines and their operation. Counteracting the wear of cooperating elements is a problem mainly occurring at the construction stage, where the material and lubrication of cooperating parts are determined. [3]

\section{DLC coating}

One of the key and most popular solutions to the problem are technological methods, such as coating the original material with a coating corresponding to the required properties. Increasingly, attention is paid to carbon-based coatings due to its characteristics and physical properties. A very good answer in this matter is the DLC coating (Diamond-Like Carbon), which is a combination of carbon structurally corresponding to diamene and carbon with bonds adequate for graphite. Owing to such a combination, the DLC coating is characterized by passivity and chemical stability, high hardness, special resistance to abrasive and tribological wear, thermal conductivity, low coefficient of thermal expansion, high elasticity index and fracture toughness. All these features meet the expectations of the constructors and, to a large extent, solve the problem of seizing the element, ensuring the extension of the life of the coated base material, and thus a noticeably fewer failures of machinery mechanisms. Diamond-like coatings can be deposited on the base material in various ways. Techniques used so far are the sputtering, pulsed laser, PVD and CVD ion beam and PACVD plasmas. [3][4]

\section{Comparative study}

Comparative tests carried out on samples of tool steel of high-speed uncoated and highspeed tool steel with a DLC coating are fully reliable, representative of the actual operating conditions of the components in machines with a reciprocating mechanism.

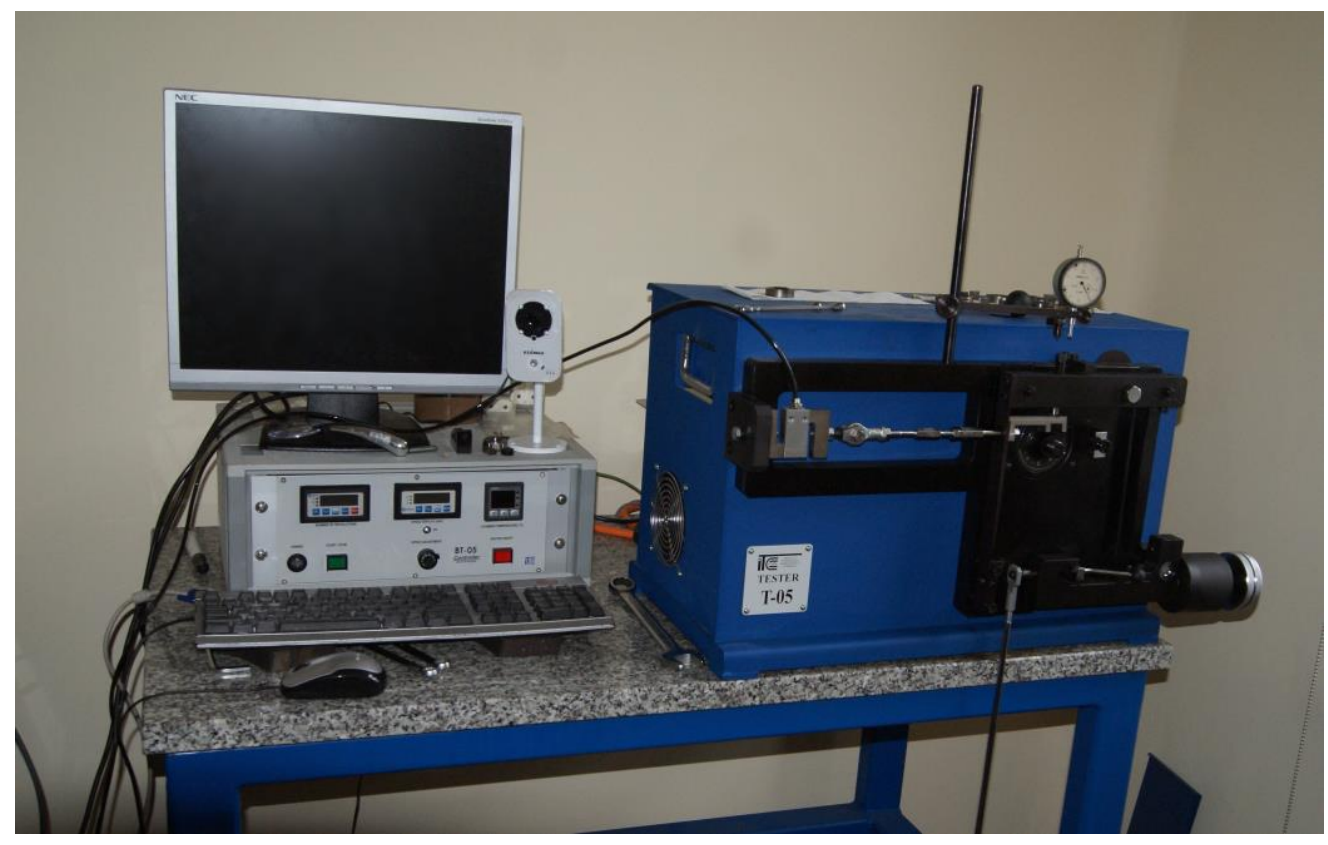

Fig.1. Test stand, tester T-05. [5] 
Samples were tested on a T-05 roll-block tester (Fig.1). The possibilities offered by the tester include setting the speed, resetting or setting the exact number of revolutions, temperature and load. The tester also has a computer program that allows you to test the measurement channels, run a research run, and prepare and print a report. The test procedure was the same for both samples and consisted of mounting a test sample and counter-sample in the test machine, running the computer program and setting the number of revolutions, load and temperature. [6]

Testing of the base sample (without coating)

Table 1. Test parameters.

\begin{tabular}{|c|c|c|}
\hline Sample & \multicolumn{2}{|c|}{ No. 1 } \\
\hline Rotation speed & 100 & $\mathrm{rpm}$ \\
\hline Load & 1 & $\mathrm{~kg}$ \\
\hline Test time & 3 & $\mathrm{~h}$ \\
\hline Sample material (block) & \multicolumn{2}{|c|}{ SW7M } \\
\hline Counter-sample material (roll) & \multicolumn{2}{|c|}{ SW7M } \\
\hline Lubrication & \multicolumn{2}{|c|}{ Yes } \\
\hline
\end{tabular}

Table 2. Parameters of samples before testing.

\begin{tabular}{|c|c|c|}
\hline \multirow{2}{*}{ No. } & \multicolumn{2}{|c|}{ Weight [g] } \\
\cline { 2 - 3 } & Sample (block) & $\begin{array}{c}\text { Counter-sample } \\
\text { material (roll) }\end{array}$ \\
\hline 1. & 8,3727 & 22,9256 \\
\hline 2. & 8,3726 & 22,9241 \\
\hline 3. & 8,3726 & 22,9169 \\
\hline 4. & 8,3726 & 22,9169 \\
\hline 5. & 8,3726 & 22,9169 \\
\hline Av. & 8,37262 & 22,92008 \\
\hline
\end{tabular}

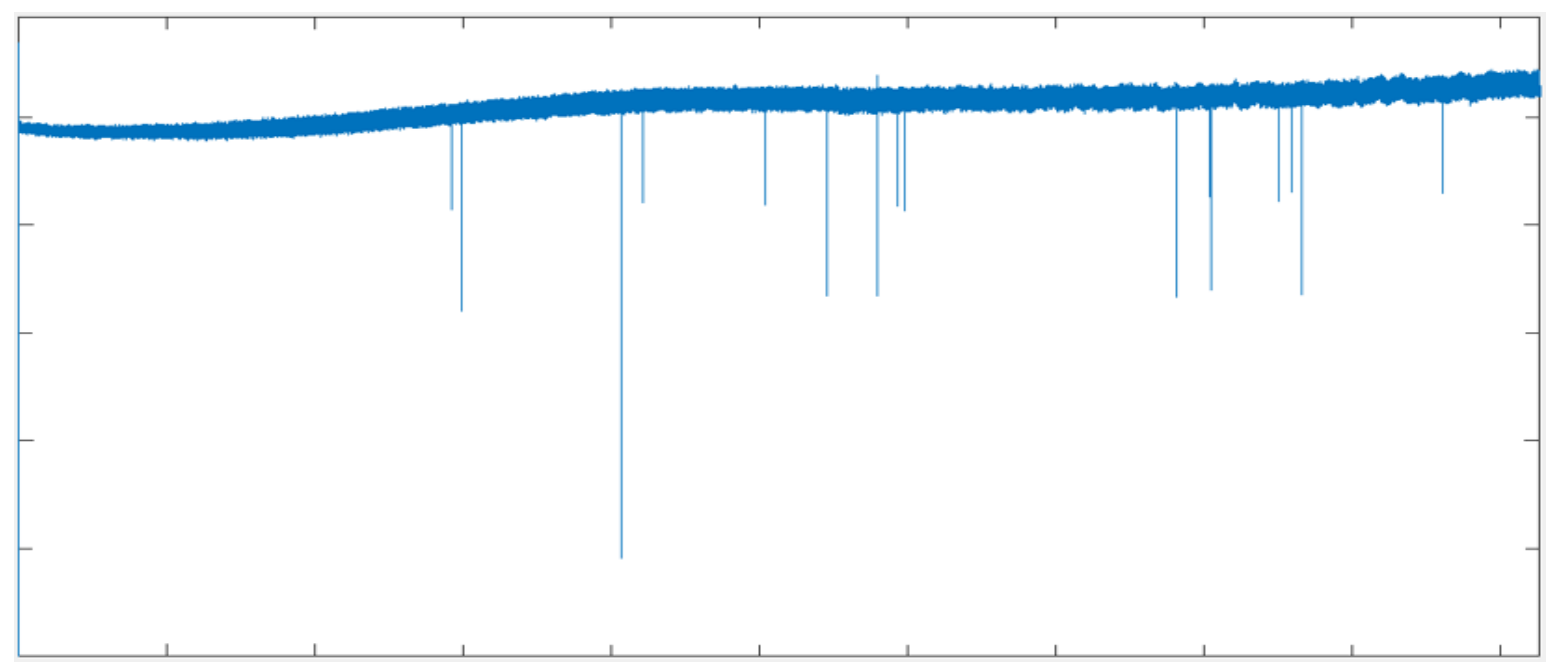

Fig.2. Friction plot of SW7M sample. [5] 
Table 3. Parameters of samples after testing.

\begin{tabular}{|c|c|c|}
\hline \multirow{2}{*}{ No. } & \multicolumn{2}{|c|}{ Weight [g] } \\
\cline { 2 - 3 } & Sample (block) & $\begin{array}{c}\text { Counter-sample } \\
\text { material (roll) }\end{array}$ \\
\hline 1. & 8,3726 & 22,9135 \\
\hline 2. & 8,3727 & 22,9135 \\
\hline 3. & 8,3726 & 22,9151 \\
\hline 4. & 8,3725 & 22,9251 \\
\hline 5. & 8,3725 & 22,9251 \\
\hline Av. & 8,37258 & 22,91846 \\
\hline
\end{tabular}

The SW7M high-speed steel sample without DLC coating was tested together with a counter-sample made of the same material. The average weight of the sample before the test differs from the average weight after the test, which indicates a significant loss of material and loss of mass of the element.
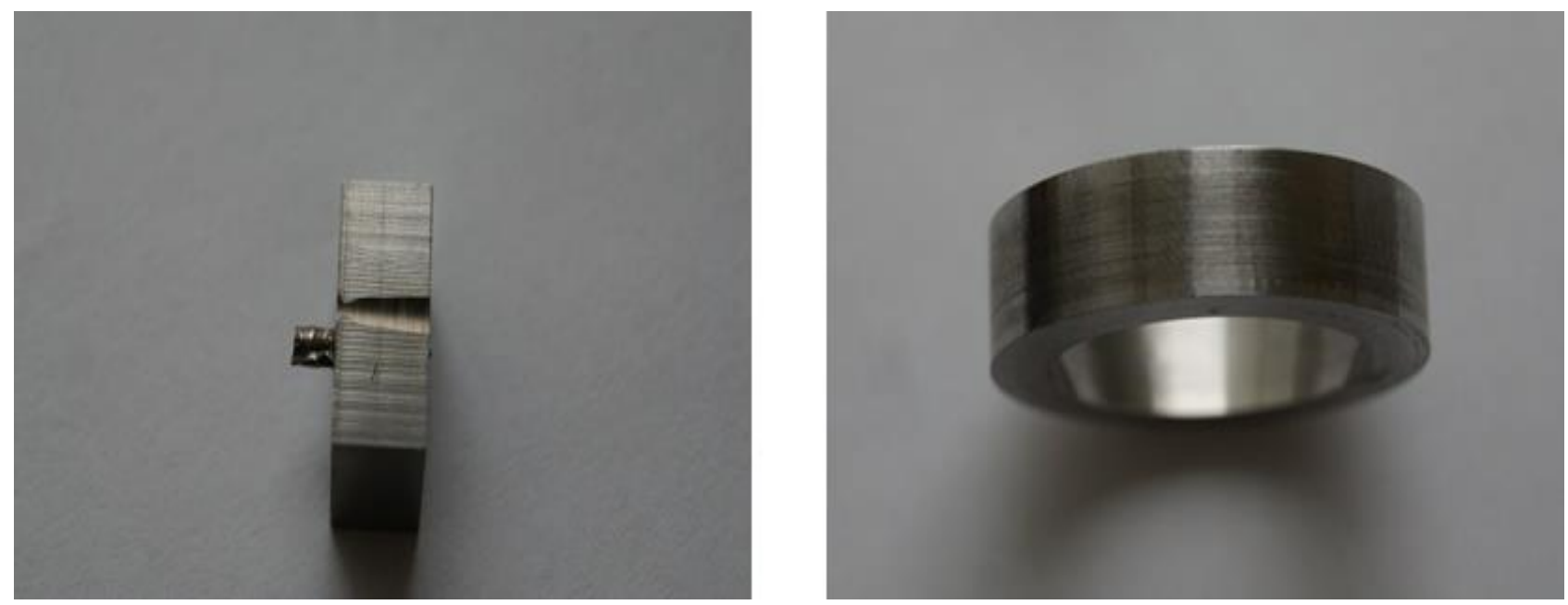

Fig.3. Sample and counter-sample of high-speed steel without coating after testing. [5]

Testing of a sample with a DLC coating

Table 4. Test parameters.

\begin{tabular}{|c|c|c|}
\hline Sample & \multicolumn{2}{|c|}{ No. 2 } \\
\hline Rotation speed & 100 & $\mathrm{rpm}$ \\
\hline Load & 1 & $\mathrm{~kg}$ \\
\hline Test time & 3 & $\mathrm{~h}$ \\
\hline Sample material (block) & \multicolumn{2}{|c|}{ SW7M+DLC } \\
\hline Counter-sample material (roll) & \multicolumn{2}{|c|}{ SW7M+DLC } \\
\hline Lubrication & \multicolumn{2}{|c|}{ Yes } \\
\hline
\end{tabular}


Table 5. Sample weight.

\begin{tabular}{|c|c|c|}
\hline \multirow{2}{*}{ No. } & \multicolumn{2}{|c|}{ Weight [g] } \\
\cline { 2 - 3 } & Sample (block) & $\begin{array}{c}\text { Counter-sample } \\
\text { material (roll) }\end{array}$ \\
\hline 1. & 8,3830 & 22,9500 \\
\hline 2. & 8,3830 & 22,9503 \\
\hline 3. & 8,3831 & 22,9501 \\
\hline 4. & 8,3829 & 22,9502 \\
\hline 5. & 8,3830 & 22,9500 \\
\hline Av. & 8,3830 & 22,95012 \\
\hline
\end{tabular}

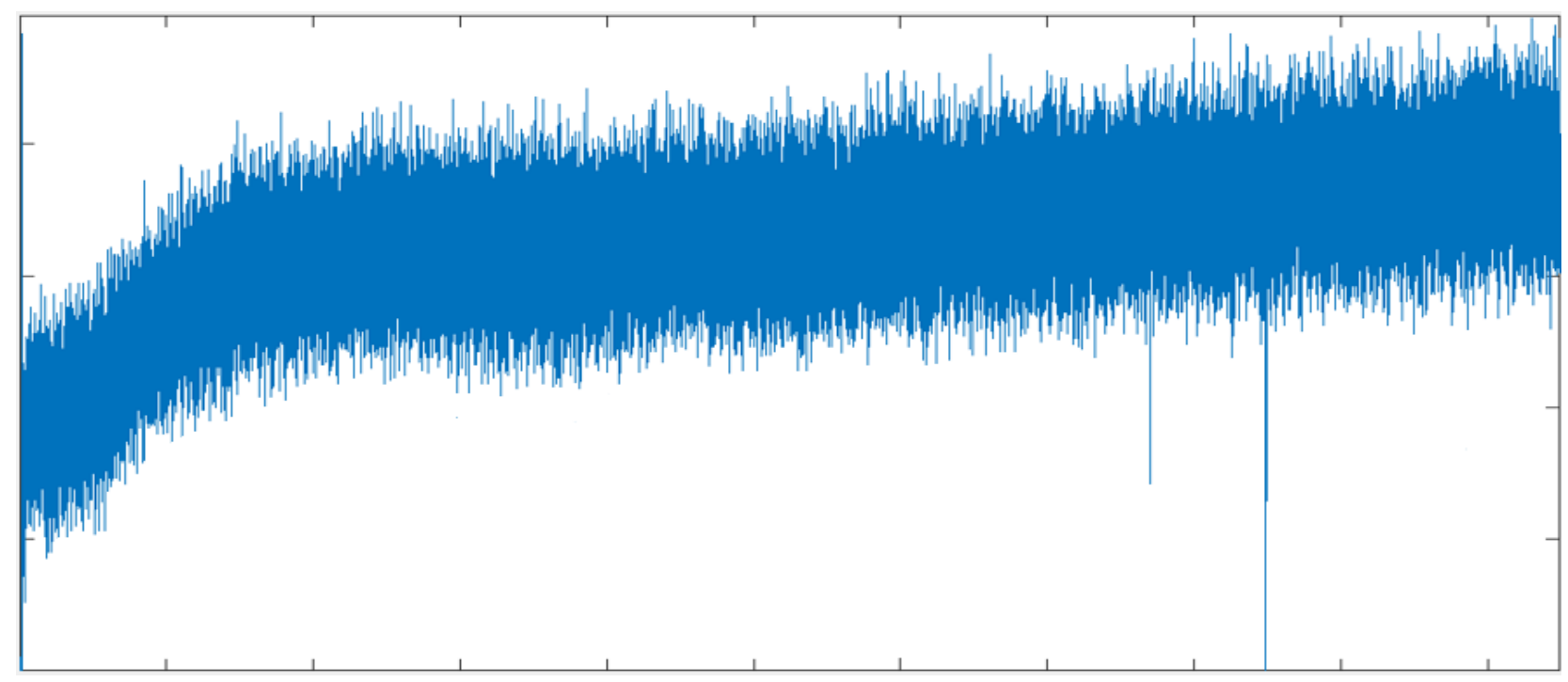

Fig.4. Friction plot of the SW7M + DLC sample. [5]

Table 6. Sample weight.

\begin{tabular}{|c|c|c|}
\hline \multirow{2}{*}{ No. } & \multicolumn{2}{|c|}{ Weight [g] } \\
\cline { 2 - 3 } & Sample (block) & Sample (block) \\
\hline 1. & 8,3830 & 22,9501 \\
\hline 2. & 8,3829 & 22,9494 \\
\hline 3. & 8,3829 & 22,9504 \\
\hline 4. & 8,3831 & 22,9503 \\
\hline 5. & 8,3831 & 22,9504 \\
\hline Av. & 8,3830 & 22,95012 \\
\hline
\end{tabular}

The SW7M + DLC fast tool steel sample was tested with a counter-sample made of the same material. Weight of the sample and counter-sample after the test does not differ from the state before the test. 

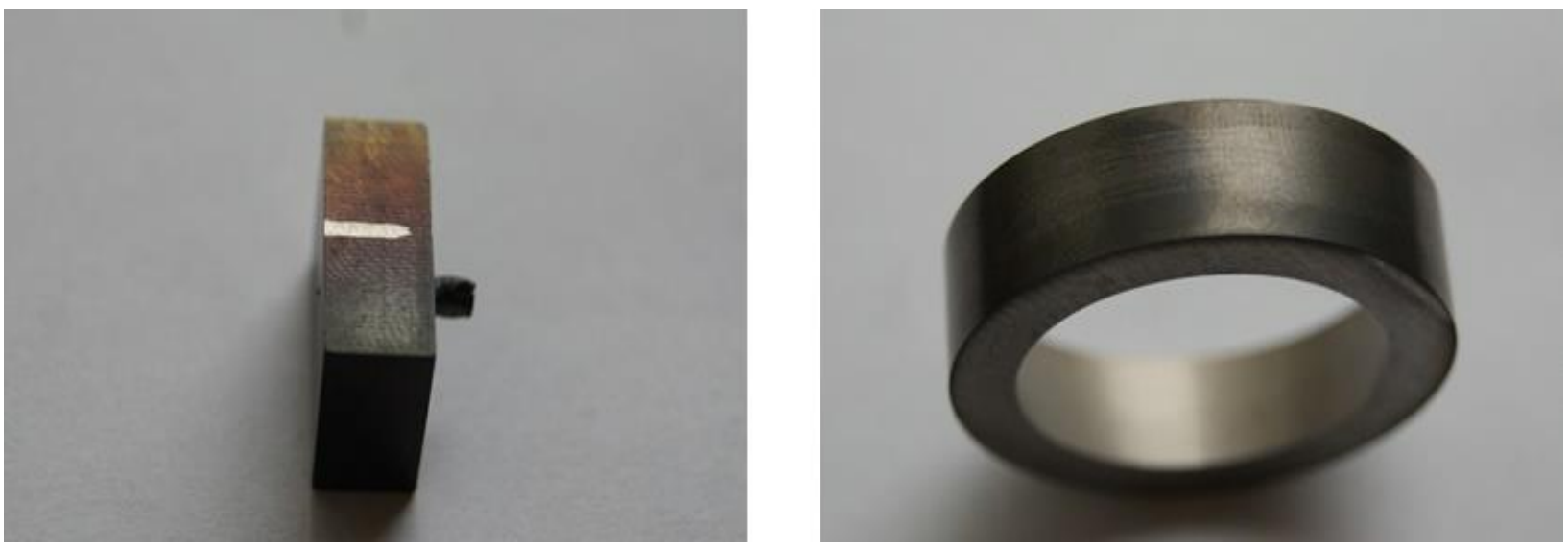

Fig.6. Sample and counter-sample of high-speed steel with DLC coating after testing. [5]

\section{Conclusion}

The purpose of this work was to analyze the tests carried out on samples of high-speed steels SW7M and SW7M + DLC in terms of their resistance to abrasive wear. The tests clearly show that the sample with the DLC coating showed better resistance to abrasion, its mass did not change, and only the topcoat layer was removed. However, the sample and counter-sample without the coating was destroyed, and on its surface a distinct loss is visible, which is confirmed by the mass test results.

The phenomenon of abrasive wear occurring in operation excludes hundreds of machines every year. DLC coating allows to reduce the effects of this phenomenon. DLC coating of elements co-paired with others, between which there is friction, would allow extending the life and service life of many machines. The widespread use of DLC coating for components could prove to be a breakthrough in technology and significantly affect its further development.

\section{References}

[1] U.Fischer, M.Heinzler, F.Näher, H.Paetzold, substantive development of the Polish version J.Potrykus, "Poradnik mechanika” (in original „Tabellenbuch Metal”), chapter „4.Materiałoznawstwo”, Warsaw, Poland, 2008, pp.115-200

[2] R.Fischer, R.Gscheidle, B.Hohmann, W.Keil, J.Mann, B.Schlögl, B.Steidle, A.Wimmer, G.Wormer, substantive development of the Polish version J.Potrykus, "Poradnik techniki samochodowej” (in orginal „Tabellenbuch Kraftfahrzeugtechnik”), chapter „4.Materiałoznawstwo”, „6.Wiedza fachowa”, Warsaw, Poland, 2010, pp.158-200, pp.220388

[3] D.Ozimna, M.Madej, “Ocena właściwości jedno- i wielowarstwowych powłok DLC” in "Tribologia”, Kielce, Poland, 2010, pp.119-135.

[4] M.Madej, D.Ozimna, "Właściwości tribologiczne powłok DLC" in "Tribologia", Kielce, Poland, 2012, pp.95-102.

[5] Own materials belonging to the author of the article.

[6] Zakład Tribologii, "Instrukcja obsługi systemu pomiarowo-sterującego testera typu rolkaklocek T-05”, Radom, Poland, 2016, pp.3-8. 